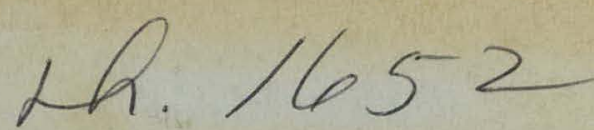

BNL-NCS-50717

\title{
PANEL ON REFERENCE NUCLEAR DATA AND SURVEYS OF REFERENCE DATA REQUIREMENTS
}

\author{
Edited by \\ T.W. Burrows and S. Pearlstein
}

September 1977

INFORMATION ANALYSIS CENTER REPORT

BROOKHAVEN NATIONAL LABORATORY ASSOCIATED UNIVERSITIES, INC. UPTON, NEW YORK 11973

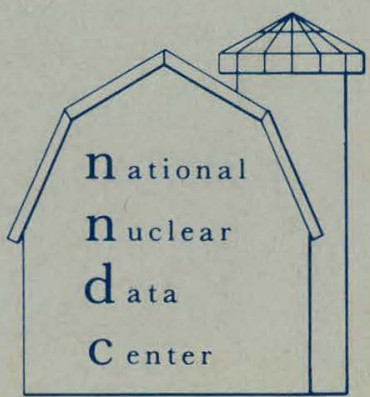




\section{DISCLAIMER}

This report was prepared as an account of work sponsored by an agency of the United States Government. Neither the United States Government nor any agency Thereof, nor any of their employees, makes any warranty, express or implied, or assumes any legal liability or responsibility for the accuracy, completeness, or usefulness of any information, apparatus, product, or process disclosed, or represents that its use would not infringe privately owned rights. Reference herein to any specific commercial product, process, or service by trade name, trademark, manufacturer, or otherwise does not necessarily constitute or imply its endorsement, recommendation, or favoring by the United States Government or any agency thereof. The views and opinions of authors expressed herein do not necessarily state or reflect those of the United States Government or any agency thereof. 


\section{DISCLAIMER}

Portions of this document may be illegible in electronic image products. Images are produced from the best available original document. 


\title{
PANEL ON REFERENCE NUCLEAR DATA AND SURVEYS OF REFERENCE DATA REQUIREMENTS
}

\author{
Edited by \\ T.W. Burrows and S. Pearlstein
}

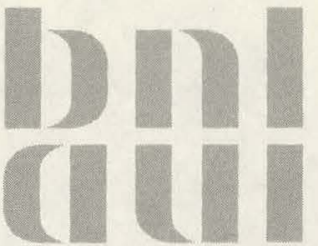

September 1977

$$
\begin{aligned}
& \text { This report was prepared as an account of work } \\
& \text { sponsored by the United States Government. Neither the } \\
& \text { United States nor the United States Department of } \\
& \text { Energy, nor any of their employees, nor any of their } \\
& \text { contractors, subcontractors, or their employees, makes } \\
& \text { any warranty, express or implied, or assumes any legal } \\
& \text { liability or responsibility for the accuracy, completeness } \\
& \text { or usefulness of any information, apparatus, product or } \\
& \text { process disclosed, or represents that its use would not } \\
& \text { infringe privately owned rights. }
\end{aligned}
$$

NATIONAL NUCLEAR DATA CENTER

\section{BROOKHAVEN NATIONAL LABORATORY}

ASSOCIATED UNIVERSITIES, INC.

UNDER CONTRACT NO. EY-76-C-02-0016 WITH THE

UNITED STATES DEPARTMENT OF ENERGY 
N O T I C E

This report was prepared as an account of work sponsored by the United States Government. Neither the United States nor the United States Department of Energy (DOE), nor any of their employees, nor any of their contractors, subcontractors, or their employees, makes any warranty, express or implied, or assumes any legal liability or responsibility for the accuracy, completeness or usefulness of any information, apparatus, product or process disclosed, or represents that its use would not infringe privately owned rights.

Printed in the United States of America

Available from

National Technical Information Service

U.S. Department of Commerce

5285 Port Royal Road

Springfield, VA 22161

Price: Printed Copy $\$ 4.50$; Microfiche $\$ 3.00$

October 1977

660 copies 
TABLE OF CONTENTS

II. Meeting Attendees and Current Membership . . . . . . . . . . . . 2

III. Summary of Minutes of October 19, 1976 Meeting of the Panel on

Reference Nuclear Data . . . . . . . . . . . . . . . 4

IV. Surveys of Reference Data Requirements

A. American Nuclear Society Radiation Protection and Shielding Division Survey Results . . . . . . . . . . . . .

B. The Institute of Electrical and Electronic Engineers, Nuclear Science and Plasma Society, Survey Results . . . .

C. The American Society for Testing of Materials, E-10 Committee, Survey Questionnaire . . . . . . . . .

D. American Nuclear Society, Isotopes and Radiation Division Survey Questionnaire (Proposed) 


\section{Introduction}

A large number of information centers are engaged in the compilation and evaluation of nuclear data. The U.S. Energy Research and Development Administration and the National Nuclear Data Center (NNDC) at Brookhaven National Laboratory suggested that the activities of these centers might be served beneficially by the advice of a committee representing the users of nuclear data.

On October 19, 1976, an organizational meeting of the Panel on Reference Nuclear Data was held at Brookhaven National Laboratory by the NNDC. Representatives of the various technical societies which encompass the users of nuclear data were invited. Also, representatives of the various nuclear' data centers, funding agencies, and publishers were also present.

Outgrowths of this meeting were a Source List of Nuclear Data Bibliographies, Compilations, and Evaluations which will be revised periodically and a plan to survey the needs of the scientific community as an aid in the planning of information center activities. The current Source List is available as the report BNL-NCS-50702. Examples of surveys used to poil Technical Society memberships are included in this report. 
II. Meeting Attendees and Current Membership

\section{List of Attendees}

Panel on Reference Nuclear Data

October 19, 1976

Brookhaven National Laboratory

Member Organizations

American Association of Physicists in Medicine
American Chemical Society
Nuclear Chemistry \& Technology Division
American Nuclear Society
Controlled Nuclear Fusion Division
Isotopes and Radiation Division
Radiation Protection \& Shielding Division
Reactor Physics Division
American Society for. the Testing of Materials
Committee E-10, Nuclear Applications and
Measurements of Radiation Effects
Health Physics Society
Institute of Electrical \& Electronic Engineers
Nucledr Science and Plasma Society

National Council on Radiation Protection \& Measurements

Radiation Research Society

Society of Nuclear Medicine

\section{Observers}

Academic Press

American Institute of Physics

American Physical Society, Nuclear

Division

Atomic Data and Nuclear Data Tables

Energy Research \& Development Administration NBS Radioactivity Section

National Standard Reference Data System

National Research Council, National Academy of Science

Nuclear Regulatory Commission

Data Centers

Paul Feller, US Public Health Service

Nathan E. Ballou, BNW

Richard Lambrecht, BNL

Don Dudziak, LASL

Michae1 D'Agostino, Grumman Jack Trombka, NASA Goddard (absent)

Chuck Weisbin, ORNL

Walter Kato, BNL

Bi11 Morgan, BNW

Charles Meinhold, BNL

James Cline, Nuc. Env. Serv.

Finis Hio Southworth, U. of Ill. (for Geo. H. Miley, U. of I11.)

Harald Rossi, Columbia U.

Harald Rossi, Col. U. (also NCRPM) Joe Coyne, NBS (for Randy Caswe1I, NBS)

Harold Atkins, BNL (for Robert Rohrer, Emory U.)

Erwin Cohen, AP

Rita Lerner, AIP

Linwood Lee, SUNY (for Stan Hanna, Stanford)

Kay Way, Duke University

Stan Whetstone, Div. Phys. Res.

Dale Hoppes, NBS

Lew Gevantman, NBS

Harry Gove, U. of Rochester

Sy Weiss, NRC

Sol Pearlstein; Charles Dunford; Norman Holden; Tom Burrows; Mulki Bhat, BNL

Bruce Ewbank, ORNL

Mike Lederer, LBL

Russ Heath, INEL

Ev Fuller, NBS 
Membership of Panel on Reference Nuclear Data

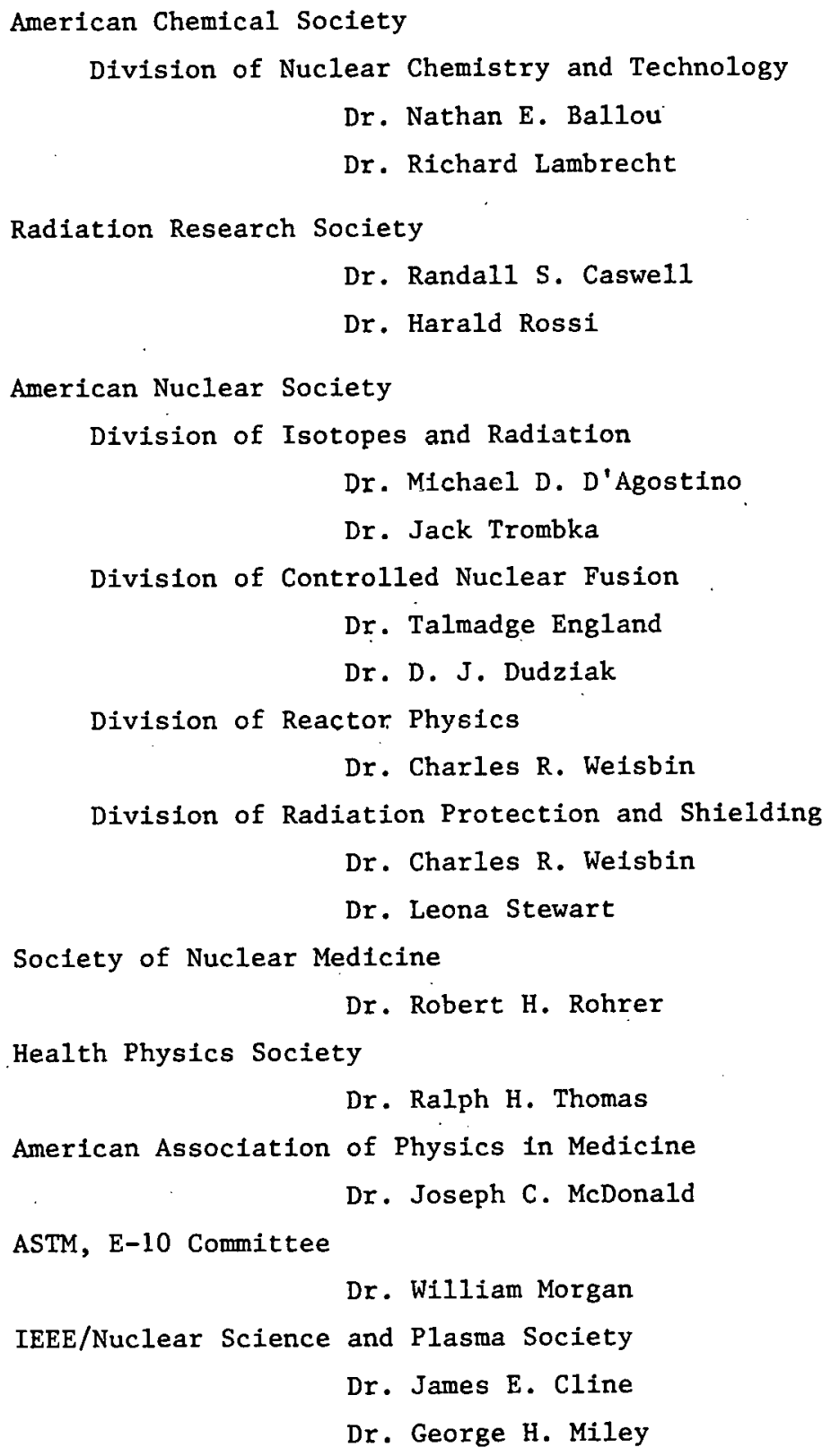


III. Summary of Minutes of October 19, 1976 Meeting of the Panel on Reference Nuclear Data

J. Hendrie, Chairman, Department of Applied Science, Brookhaven National Laboratory (BNL), and $\mathrm{S}$. Whetstone; representing the Divfsion of Phystcal Research, Energy. Research and Development Administration (DPR/ERDA), welcomed the Panel to Brookhaven. In his welcoming remarks, S. Whetstone referred to the letter of D. Miller, Acting Director, DPR/ERDA, to G. Vineyard, Director, BNL, requesting the National Nuclear Data Center to assume responsibility for the-coordination_of.nuclear_data_activities.........

S. Pearlstein, BNL, opened the meeting with the observation that there are many nuclear data centers and a very. large number of centers covering o.ther. areas of data. A list of directories to these centers was distributed. Data centers engaged in related activities can be aided by the advice of an advisory group such as the Panel on Reference Nuclear Data. He also noted that the Panel, b.y its. composition, , has.. several.desirable . characteris.tics., not fully duplicated.

by any other advisory group. These characteristics include direct communication links- between the data centers and the scientific community, direct representation. of the professional societies, a scientific balance, and independence from any special agency. The charges to the Panel suggested by S. Pearlstein included assessment of the adequacy of current compilation and evaluation efforts, recommendation of priorities, monitoring of the activities, and acceptance of new areas of responsibility as warranted. He also noted that the Panel's summary report would be useful to the data centers, the professional societies, and the funding agencies. 
PANEL ORGANIZATION

J. Cline, Nuclear Science and Plasma Society, Institute of Electrical. and Electronic Engineers, was chosen to chair the Panel and the National Nuclear Data Center, BNL, was approved as the Panel secretarlat.

Prior to continuing with the Agenda, S. Pearlstein, BNL, noted that while the organizations represented on the Panel would profit from a greater awareness of the influence on the data centers, the centers also needed the Panel as a method of improving communications with the scientific community.

SOURCE MATERIAL

N. Holden, BNL, discussed the various sources of bibliographic, compiled, and evaluated data currently available. A preliminary list of these sources was made available to the Panel.

COORDINATION

S. Pearlstein, BNL, summarized the coordination activities of the National Nuclear Data Center (NNDC), its relationship with various funding agencies and with various US and international comittees and organizations. The Center is funded by three divisions of ERDA, the Electric Power Research Institute (EPRI), and, until recently, the Defense Nuclear Agency. At the request of the Divisions of Physical Research and of Reactor Development and Demonstration of ERDA and of EPRI, the Center coordinates nuclear data compilation and evaluation efforts in the US and with similar international activities.

The US activities coordinated by the NNDC consists of the Cross Section Evaluation Working Group (CSEWG), a group of over 20 governmental, industrial, and university laboratories involved in the measurement, evaluation, and use of standard reference nuclear data; and the Nuclear Data Network, consisting of 6 data centers. CSEWG meets at least twice a year to assemble the Evaluated Nuclear Data File (EINF/B), a well-referenced, computerized data base which is revised every two to three years. The Nuclear Data Network consists 
of data centers with overlapping interest in nuclear data and currently meet every six months under the coordination of the NNDC to minimize duplication of efforts, produce timely revisions of reference nuclear data publications, and to provide other services required by the scientific community.

The NNDC exchanges information and cooperates with the International Atomic Energy Agency (IAEA), the Nuclear Energy Agency (NEA), and various USSR data centers to achieve the same goals internationally as the US networks aim for. The interaction of the NNDC with other groups was summarized.

There are a large number of advisory and coordinating groups for nuclear data. The work of the NNDC is reviewed by a specially appointed committee and also by the Department of Applied Sclence Visiting Committee. The Center also reports to the ERDA Advisory Committee on Reactor Physics and Nuclear Data Committee as well as the NEA. counterparts of these two committees and to the International Nuclear Data Committee (INDC) of the IAEA. The Committee on Data for Science and Technology (CODATA) meets biennially to discuss data management and evaluations for a wide range of data including nuclear data.

H. Gove, Chairman, Panel on Nuclear Data Compilations, National Research Council - National Academy of Sciences Committee on Nuclear Science, summarized the history and charter of his Panel. The Panel would be concerned mainly with the state of reference data as it affects the basic nuclear science community, communicating these concerns directly to the Division of Physical Research, ERDA, and to other interested funding agencies.

L. Gevantman, National Standard Reference Data System (NSRDS), summarized the history and responsibility of NSRDS, which is part of the National Bureau of Standards Office of Standard Reference Data. NSRDS aids and encourages the work of centers engaged in the critical evaluations of data. The broad scope of this activity is divided into seven catagories (nuclear, atomic and molecular, solid state, colloid and surface properties, thermodynamics and transport properties, chemical kinetics, and the mechanical 
properties of materials). In the area of nuclear properties, the NSRDS cooperates closely with ERDA, providing supplementary support in some areas. The NSRDS publishes standard reference data in the Journal of Physical and Chemical Reference Data, in the NBS special publications and in other publications. He also mentioned the Standard Reference Data Act and the responsibilities of the Secretary of Commerce under this act.

\section{STATUS REPORTS}

National Nuclear Data Center, BNL: Several new features of the Computer Index of Neutron Data (CINDA) have been implemented. These include blocking of related references, treatment of obsolete progress reports, and the data index line. An archival volume of CINDA is being planned for 1978, containing references prior to 1973.

The NNDC experimental neutron data files are fairly complete for data produced since 1970, the start of the international exchange of data. Older missing data are being compiled on a time-available basis. Improvements in the output formats are being planned.

\section{The Evaluated Nuclear}

Data File (ENDF) is currently being revised. The new release, ENDF/B-V, is planned for early 1978. A special purpose file of neutron and decay data for the actinides is already under review. The special purpose files on neutron dosimetry and fission products are also being revised and new special purpose gas production and activation files are planned.

New activities in the

area of charged particle reaction data have begun. The first activity of the Center will be production of a computerized index and published bibliography of integral charged particle nuclear data. The international exchange of charged particle reaction data has begun. Planned evaluation efforts include neutron source, fusion, and isotope production reactions.

The NNDC will add one evaluator and begin mass chain evaluations. Work has begun on the 
implementation of the Center's assigned service functions.

Nuclear Data Project, ORNL: The Nuclear Data Project has added three evaluators to their staff. The first international exchange file of evaluated nuclear structure and decay data has been completed. Publication of computer-produced Recent References and Nuclear Data Sheets continue.

The Project has also been

active in preparing decay. data for applied users. These activities include ORNL-5114, containing data on 193 radio-nuclides, preparation of information. for a National. Council on Radiation Protection and Measurement. handbook, . containing. dat.a on 220. radio-nuclides (including the data in ORNL-51.14), and aiding the Environmental Safety Division of ORNL in preparing data on an additional. 215 radio-nuclides.

Photonuclear Data Center, NBS: The Center compiles and evaluates nuclear reaction data in which electromagnetic radiation are involved in the entrance or exit channels. With the cooperation of the National Standard Reference Dața System, they publish bibliographies of photonuclear data on a periodic basis. A current evaluation of photonuclear reactions on target nuclei from lithium through oxygen-16 is $90 \%$ complete.

Table of Isotopes Project, LBL: Evaluations for the seventh edition of the Table of Isotopes will be completed in February 1977. Publication of the seventh edition should follow in about six months. They will begin mass chain evaluations in the spring of 1977. Their computerization of nuclear structure and decay data have emphasized publication formats.

Physics Group, INEL: The activities of the Group interfaces across a whole spectrum of applied needs and the Group has the major responsibility for decay data in ENDF/B. They have proposed to add one evaluator and will begin mass chain evaluations. 
Fay Ajzenberg-Selove, Univ. of Pennsylvania: The evaluation of mass chains between $A=5$ and $A=20$ is continuing.

National and International Coordination: An April meeting at Brookhaven resulted in the formation of a network of US centers to coordinate national activities in evaluating nuclear structure and decay data. Responsibilities for mass chain evaluations were assigned and future publications were discussed. This meeting was followed by a similar international meeting in Vienna sponsored by the IAEA.

\section{PUBLICATION ECONOMICS}

There were brief presentations by E. Cohen, Academic Press, K. Way, Editor, Atomic Data and Nuclear Data Tables, and R. Lerner, American Institute of Physics, on publication economics. E. Cohen discussed the pricing of scientific books, the amount of profit made on scientific books and journals, the need for camera-ready copy by the publishers so that compilations could be published economically, and various postal restrictions on journal distribution. K. Way briefly outlined the history of Atomic Data and Nuclear. Data Tables, emphasized the need of secondary publications such as the Tables, and discussed the points authors should consider when they try to find a publisher. R. Lerner discussed the subscription size and number of. off-print requests for the Journal on Physical and Chemical Reference Data and a current proposal for data-tagging in other A.I.P. journals.

\section{PROJECTED PROGRESS AND DIFFICULTIES IN EXISTING PROGRAMS.}

S. Pearlstein, BNL, used the Wall Chart of the Nuclides as an example of difficulties with existing programs. Although Knolls Atomic Power Laboratory will produce another Chart, there is no continuing long-term commitment to produce a chart.

\section{PANEL DISCUSSION}

Discussion of reference data requirements and specific actions resulted in the following actions to be taken: 
Summary of Specific Actions to be taken by Panel on Reference Nuclear Data.

1. Bibliographic Information Source List

A. BNL should upgrade the source list so that it

1) is complete and up to date,

2) includes costs and availability of the sources listed, and

3) is reduced somewhat in size to facilitate mailing.

B. BNL shall plan to update this source list at least annually as a continuing effort.

c. Committee members shall recommend methods to and solicit suggestions from their societies as to the best methods for distributing these lists and updates to their members. These recommendations shall be in the final summary.

2. Current Data Files \& Compilations

Committee members should, in conjunction with their respective Societies,

A. compile a list of items of interest to their groups,

B. obtain specific comments on the wall Chart of the Nuclides, the Nuclear Data Sheets, Nuclide Tables in Handbook of Chemistry \& Physics, Gamma Ray Spectrum Catalog, and the proposed Handbook of the Isotopes as to their usefulness, formats, etc.,

C. recommend revision schedules for the master data files and publications,

D. recommend suggestions for data presentation formats,

E. recommend methods for distributing specific data to members, and

F. point out areas where the current evaluation and compilation efforts are inadequate. These areas could include such things as high-energy cross sections for dosimetry, particulate reaction cross sections required for fusion studies, etc. Results of these recommendations shall be included in the meeting summary report.

3. Surveys

Copies of two survey forms regarding nuclear data compilations are supplied to members of the comittee. The one survey was circulated to the research community and the other to a more general audience of basic and applied users. It is, however, up to the society representatives to tailor the survey to the needs of his particular society. The survey should address the questions in item 2. above. The results of a survey by each society shall be included in the final summary.

4. Panel Organization

The societies shall select permanent members to serve on the panel for terms of two years. The terms of the two members from each society or division. should be staggered so that there would be some continuity in the membership.

It is suggested that the Health Physics Society invite a member of the Power Reactor Health Physics Society to serve on the Panel.

The panel will decide upon a date and agenda for the next meeting. The chairman suggests annual meetings but desires suggestions as to both frequency and agenda items for the meetings.

The membership and date and agenda of the next meeting will also be included in the final summary report. 
IV.A American Nuclear Society Radiation Protection and Shielding Division Survey Results

OAK RIDGE NATIONAL LABORATORY
OPERATED aY.
UNION CARBIDE CORPORATION
NUCLEAR DIVISION

POST OFFICE BOX $X$

OAK RIOGE, TENNESSEE 37830

June 23, 1977

To: Wilbur Bunch, Chaírman

Radiation Protection and Shielding Division, ANS

From: C. R. Weisbin, L. Stewart, and J. Gentry

Subject: Results of Survey to Assess Nuclear Structure and Charged Particle Data Needs of RP\&SD

\section{Overview}

Approximately 890 questionnaires were mailed to members of the Radiation Protection and Shielding Division in support of a request for information by the Panel on Reference Nuclear Data. 1 Replies received totaled 120 (113 domestic, 7 foreign). About 50\% of the replies came from private industry, $25 \%$ from universities, $20 \%$ from national laboratorifs, and $5 \%$ miscellaneous. The responses received were overwhelmingly from the applied rieutron transport community. Of the several reference sources now available, the Chart of the Nuclides received the highest rating with respect to usefulness, but there were many complaints that it is out of date and no longer available (the need for updating was also cited many times with regard to the Table of Isotopes). Updating to meet the present siate of the art seems to be of greatest importance now. There is also a definite need cited for improvement of simplicity and ease of use for all of the publications (e.g. consistency in format presentation). The response to the suggestion of a newsletter containing current information regarding availability and cost of nuclear data reference material was very enthusiastic. Specific data and applications used most frequentiy are: halflives of radioactive substances, energies and intensities of gamma rays, nuclear decay modes, and isotopic abundances. Computer codes making use of such information vary widely in scope and data format; many different codes are being used for many applications. Most of the requests for additional nuclear data information were for neutron cross sections, and we bel ieve much of this work is currently in progress under the auspices of CSEWG (e.g. dosimetry, activation and high energy neutron cross sections). In general, the need for evaluated data was rated about $20 \%$ higher than experimental data. The only additional needs cited by the respondents which may be of some interest to the panel include $(\alpha, n)$ spectra, $\alpha$ particle spectra, photo-neutron data, covariance files, and simple tabulation of $14-\mathrm{MeV}$ cross sections and cross sections averaged over a fission spectrum. These are by no means listed in order of importance; none of these items was included in any substantial number of replies.

IL. Stewart and C. R. Weisbin, letter dated February 2, 1977
CC: J. E. Cline
S. Pearlstein 
I. Compilation and Evaluation Programs Currently Underway

(A) Usefulness of reference sources (with " $\eta$ " denoting most use; others rated in increasing order with 5 indicating no interest):

1. Chart of the Nuclides

\begin{tabular}{|c|c|c|c|c|c|}
\hline $1^{\circ}$ & 2 & 3 & 4 & 5 & $\begin{array}{c}\text { no } \\
\text { response } \\
\end{array}$ \\
\hline 83 & 23 & 6 & 5 & 2 & 1 \\
\hline 23 & $\cdot 30$ & 29 & 15 & 10 & 13 \\
\hline 11 & 26 & 22 & 17 & 31 & 1 \\
\hline 24 & 31 & 20 & 15 & 15 & 15 \\
\hline 63 & 25 & 18 & 5 & 6 & 3 \\
\hline 9 & 18 & 15 & 15 & 50 & 13 \\
\hline 11 & 18 & 21 & 24 & 21 & 25 \\
\hline 4 & 9 & 14 & 21 & 56 & 16 \\
\hline 3 & 9 & 15 & 21 & 54 & 28 \\
\hline 13 & 5 & 4 & 3 & 9 & 86 \\
\hline
\end{tabular}

10. Other (see attachment $A$ )

It can be seen from Figure 1 that Chart of the Nuclides and Table of Isotopes are rated most useful. . There seems to be little interest in Energy Levels of Light Nuclei, Charged Particle Reaction List, and Charged Particle Cross Sections, $Z=1$ to 9 . Less than $30 \%$ of the respondents listed other sources needed over these nine polled.

(B) What improvements would you like to see incorporated in the above?

There were 55 responses to this portion of the question. The need for more frequent publication or updating was mentioned by $43 \%$ of those responding, with Table of Isotopes mentioned most frequently. At this time, updating to meet the present state of the art seems to be more important than setting up publication schedules. There was a definite need cited to improve simplicity and ease of use. The same format presentation of various publications would be desirable. (Complete list of comments appears in attachment B.) 
(C) Were you aware of availability and cost of these references?

\begin{tabular}{llll}
\multicolumn{2}{c}{ Availiability } & \multicolumn{2}{c}{ Cost } \\
yes & no & yes & no \\
$36 \%$ & $64 \%$ & $25 \%$ & $75 \%$
\end{tabular}

Would a periodic newsletter be of interest?

$90 \%$ were in favor of a newsletter.

There were suggestions that this information might be included in the RSIC or BNL newsletters, rather than publishing a separate newsletter, but response to this question in general was very enthusiastic. Suggestions for frequency of publication ranged from quarterly to annualiy, with every 6 or 12 months. most desirable. (Complete list of comments appears in. attachment $\mathrm{C}$.)

II. Specific Data and Application Requirements

(A) Which current- applications. require nuclear structure or charged. particle data?

Many of those responding to this question rated the data from" " 1 " to " 5 " as in question I. Others checked data-which were applicab-le. The following table shows totals for both types of responses:

Type of Data check $1 \quad 2 \quad 2 \quad 3 \quad 4 \quad 5 \quad$ response

1) Half-lives of radioactive substances

2) Isotopic abuncances $\begin{array}{lllllll}71 & 19 & 3 & 3 & 1 & 0 & 23\end{array}$

3) Nuclear masses $\begin{array}{lllllll}66 & 15 & 4 & 5 & 2 & 0 & 28\end{array}$

4) Nuclear spins and moments

$\begin{array}{llllllll}29 & 4 & 6 & 6 & 5 & 4 & 66\end{array}$

$\begin{array}{llllllll}7 & 2 & 0 & 1 & 5 & 15 & \cdots & 90\end{array}$

5) Nuclear decay modes and genetic (parentdaughter) relationships

$\begin{array}{lllllll}66 & 13 & 6 & 2 & 3 & 1 & 29\end{array}$

6) Activation cross sections

$\begin{array}{llllllll}60 & 13 & 8 & 0 & 3 & 2 & 34\end{array}$


Type of Data check $1 \quad 2 \quad 3 \quad 4 \quad 5 \quad \begin{gathered}\text { no } \\ \text { response }\end{gathered}$

7) Energies and intensities of radiations:

$\begin{array}{lrrrrrrr}\text { Gamma rays } & 72 & 20 & 5 & 0 & 1 & 0 & 22 \\ \text { X-rays } & 44 & 8 & 9 & 2 & 4 & 2 & 51 \\ \text { Beta particles } & 52 & 11 & 4 & 4 & 2 & 3 & 44 \\ \text { Conversion electrons } & 30 & 6 & 5 & 3 & 5 & 6 & 65 \\ \text { Alpha particles } & 43 & 8 & 6 & 5 & 1 & 4 & 53\end{array}$

Other radiations (see attachment $D$ for listing)

8) Neutron capture gamma spectra
51
13
5
2
3
3
43

9) Charged-particle or photo-induced

reaction data:

$\begin{array}{llllllll}\text { Excitation functions } & 13 & 2 & 1 & 3 & 4 & 13 & 84\end{array}$

Cross sections for

specific levels

20

Angular distributions 13

Gamma-ray spectra 3

10) Nuclear level schemes 2

$\begin{array}{lllllll}31 & 9 & 6 & 5 & 0 & 5 & 64\end{array}$

11) Other types of data (see attachment $E$ for listing)

(B) List of codes used which require a nuclear data library (evaluated) as input:

It would appear that there are many people using many different codes for many different applications with data in many different formats! However, from the 81 responses to this question, it would appear that ANISN is used considerably more frequently than any other code (listed in 27 responses). Some comments on adequacy of ANISN: library adequate for transport calculations; almost adequate; has a good library supplied; adequate, but cumbersome to use. MORSE was mentioned frequently: inadequate - need good five-group libraries; mostly OK. DOT (libraries are generally adequate) and ORIGIN (inadequate for other than 3-group set; data deficient; need more $n, y$ data; need update) were also mentioned a number of times. See attachment $F$ for complete list of comments. 
(C) Additional nuclear data information required:

Most of the additional needs are being taken care of. Most of the requests were for cross sections, and this work is being done. Complete list of requests appears in attachment $G$.

III. What type of information would you give the highest rating? (again, "1" indicates top, "5" no interest)

Evaluated data rated about $20 \%$ higher than experimental data. It is interesting to note that computerized data and desk-top data were rated of almost equal value. Figure 2 shows the percentage of interest in the various types of information.

Reasons for the rankings are just about what one would expect: rapid, inexpensive accessibility (computer tapes would be more useful if easier to access). Complete list of reasons appears in attachment $H$.

IV. What additional services would you like to see implemented? How extensive should these services be?

The response to this question was diverse and impossible to summarize. Responses are listed in attachment I. 


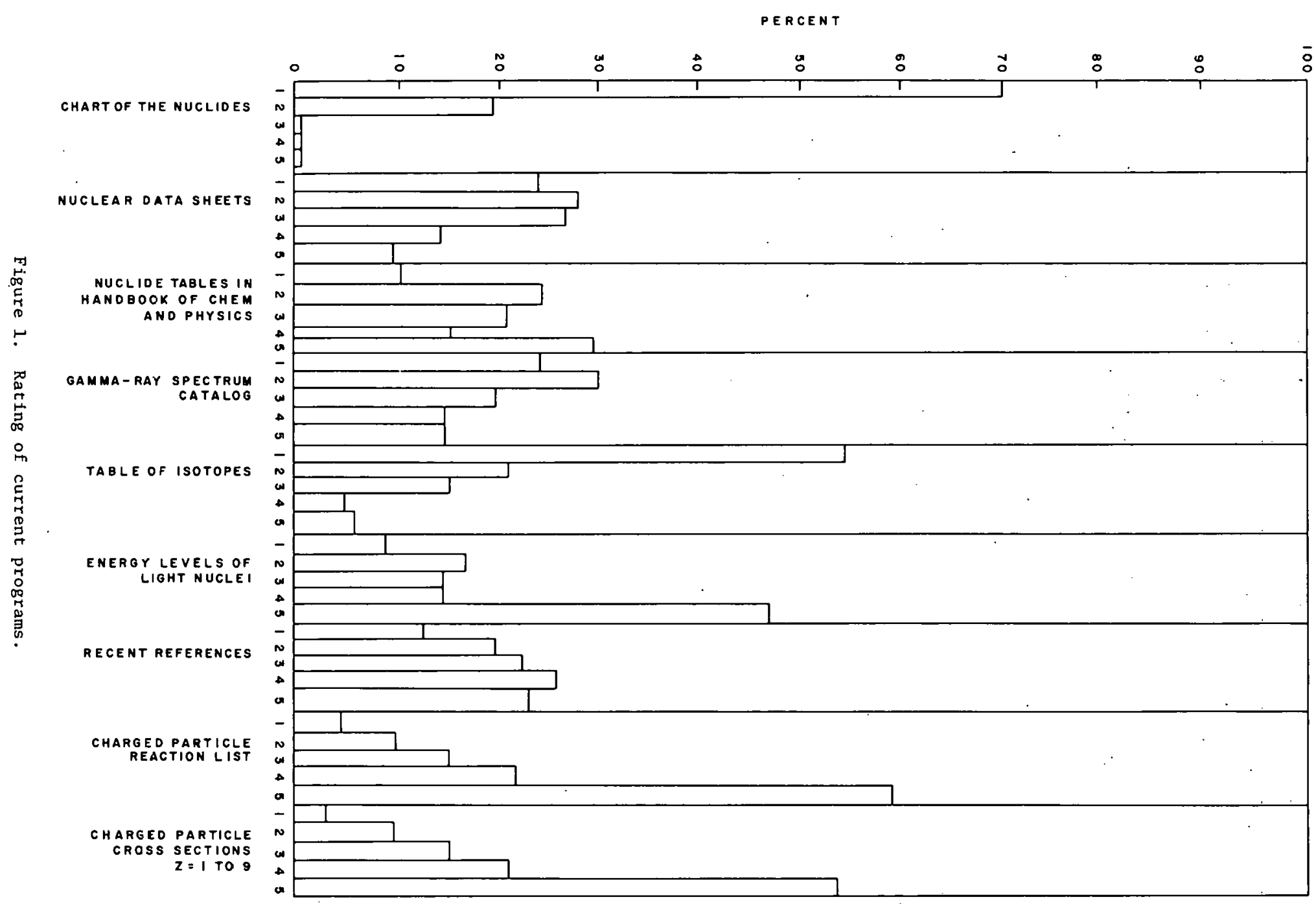


IV.B The Institute of Electrical and Electronic Engineers, Nuclear Sclence and Plasma Society, Survey Results

August 2, 1977

TO: Martin Plotkin

Nuclear Science.- \&. Plasma. Society

Institute of Electrical \& Electronic Engineers

FROM: James E. Cline

SUBJECT: Results of Survey of Nuclear Data Needs of IEEE/NSPS Members

Summary

The results of the survey were quite disappointing in that only 19 surveys were returned. The typical responder worked in..a. government

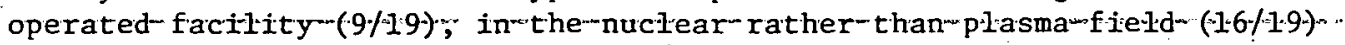
and used nuclear data frequently $(13 / 19)$. A tabulation of the results. is given on the attached. survey sheet.. Only very general. conclusions can be drawn from such a small sampling. These are as follows:

1. There is a fundamental and continuous need for general nucliear data such as half-lives; isotope-abundances, decay"modes; radiation-energies and intensities, and cross sections.

2. These are currently supplied primarily by the nuclide wall: charts,. data. sheets., tables of isotopes, and gamma-ray catalogs.

3. There is large use of out-of-date compilations and considerable desire to have more frequent updates available.

4. There is infrequent use of the data centers" - particularly NBS.

5. There appears to be considerable lack of knowledge of the availability of most of the data compilations. This may be the reason that the Data Centers are not used.

The data acquired will be used by the Panel on Reference Nuclear Data.

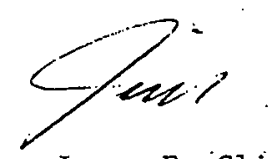

James E. Cline

JEC : def

cc: G. Miley

S. Pearlstein 
1. Personal Data

Name: (optional)

Occupation:

Name of Employer:

$$
\text { yer is a: }
$$

4 o Private Corporation

9 o Government operated installation

3 o Government contract installation

3 o University

(name of dept. or college)

$$
\text { o other }
$$

Have you recelved a similar questionnaire from a Soclety other than IEEE?

$$
30 \text { yes } 16 \text { o no }
$$

2. (a) Do you use or encounter radioisotopes, nuclear reactors, or charged-particle accelerators, or deal with nuclear properties in your work?

140 radiolsotopes 11 o accelerators

12 o nuclear properties 5 o reactors

(b) For what purpose?

5 - medical diagnostics

5 - monitoring

9 - scattered

(c) Are you concerned with plasmas in your work?

3 o partlally lontzed discharges

2 o fusion experiments

3 - fusion conceptual design

1 o lasers

2 o space plasma

3. How of ten do you use sources of nuclear data in your work (compilations, wall charts, original publications, Journals, etc.)?
130 frequently
6. occaglosally
- rarely

$$
0 \text { never }
$$

(IF THE ANSWER TO QUESTION 3 IS "NEVER", IT IS NOT NECESSARY TO ANSWER THE FOLLOWING QUESTIONS.)

4. What types of data do you require? (check any which you use)

\section{Type of data}

170 (a) Half-11ves of radloactive substances

160 (b) Isotoplc abundances

100 (c) Nuclear masses

30 (d) Nuclear spins and moments

110 (e) Neutron capture or $\mathrm{fls}_{\mathrm{s}}$ slon cross-sections

150 (f) Nuclear decay modes and genet1c (parent-daughter) relationshipg

90 (8) Means of producing radiolsotopes
4. (continued)

- (h) Energies and intensities
of radiations:

17 o gamma rays

140 X-rays

11 o beta particles

7 o conversion electrons

9 o alpha particles

- other radiations (please specify)

3 Neutrons

2 Protons

1 Electrons

6 (1) Detalled neution reaction data (energy-dependent cross-sections, resonance parameters)

5 o (j) Neutron capture gamma spectra

100 (k) Charged-particle or photo-induced reaction data:

4 o gross cross-sections (Excltation functions)

5 o cross-sections for specific levels

5 o angular distributions

8 o gamma-ray spectra

90 (1) Nuclear level schemes

20 (m) Fuston cross-sections

30 (n) Charged-particle scattering (plasmas)

elastic

nuclear elastic other

o

(o) Other types of data (please specify)

1 Human dose levels

5. How complete a listing of a given quanticy do you require? (Check one or more)

3o All reported values

50 A few of the best reported values

20 The one most precise or accurate reported value

140 A welghted average or adopted "best" value

- Other (please spectfy) 
6. What sources of nuclear tata do you consult and how frequencly do you use them? (Check appropriate boxes for any sources that you isse.)

Comp1lation

(a) Table of Isotopes, 6th edition (1967)

(b) Nuclear Data Sheets (the Journal Nuclear Data and earlier loose-leaf sheets)

(c) Nuclide "wall" charts (G.E., Bacelle N.W., or other versions)

(d) BNL-325 (the "Barn Bouk")

(e) "Light-element" corpilations (by F. AjzenbergSelove or Endt and van der Leun, published in the journal Nuclear Physics, or other (please specify)

(f) Table of Nuclides "in the Handbook of Chemistry and Physics

(g) Gamma-ray Spectrum Cácalogue - NaI(TI) - IISAEC Report ID016880

(h) Gama-ray Spectrum Catalogue - Ge(LA) - ERDA neport Aiv 1000

(1) Atomic Data for CTR ORNL-5206 and ORNL-5207 and Reactivities Illinols Report

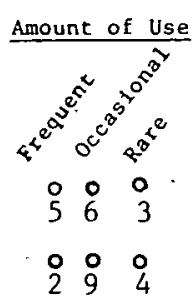

$\begin{array}{lll}\circ & \circ & 0 \\ 7 & 9 & 3\end{array}$

$\begin{array}{lll}9 & 0 & 9 \\ 3 & 3 & 5 \\ 0 & 0 & 0 \\ 2 & 2 & 4\end{array}$ $\begin{array}{lll}\circ & 0 & 0 \\ 4 & 7 & 7\end{array}$

$\begin{array}{lll}\circ & 0 & 0 \\ 1 & 7 & 7\end{array}$

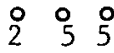

$\begin{array}{lll}\circ & 0 & 0 \\ 1 & 2 & \vdots\end{array}$

$\begin{array}{lll}\circ & 0 & 0 \\ 0 & 2 & i\end{array}$ COO-2218-17

7. In what ways may the compilations be 1 mproved? Please check any appropriate circle.

Compllation a b c d e f 8 h 1 jk 1 m no p Could cover 0000000.000000000 more requir- 1 ed categories

of data

Could cover 0000000000000000 less cate-

gories of

data

Not enough 0000000000000000 detail

Too much 0000000000000000 detail

Difficult to 0000000000000000 interpret:

1

Too much out 0.000000000000000 of date $\quad 33121$

other (please 0000000000000000 specify)

(1) Fuston Cross-Sections

8. Would you like to have the data in. different forms, such as:

- Anuther type of printed compilation (please specify)

$\begin{array}{llll}\text { (k) Atomic Data Newsletter } & 0 & 0 & 0 \\ \text { (ORNL) } & 0 & 0 & 3\end{array}$

$\begin{array}{llll}\text { (1) Charged Particle Cross- } & \circ & \circ & 0 \\ \text { Sections, Report LA-2014 } & 1 & 4 & 0\end{array}$

(m) Any "spectalized" tables of 000 speciflc properties, such

as nuclear momencs, nuclear

masses, fundamental con-

stants, electron binding energies, etc. (please specify)

(n) Data supplied by manufacturer 0 o 0 or distributor of radio- 344 Isotopes

(o) Proposid Handbood of the $\begin{array}{lll}0 & 0 & 0 \\ 1 & 6 & 1\end{array}$ Isotopes

- 00

(p) Other (please specify)

Radiological health_- 1

Nuclear Masses -

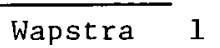

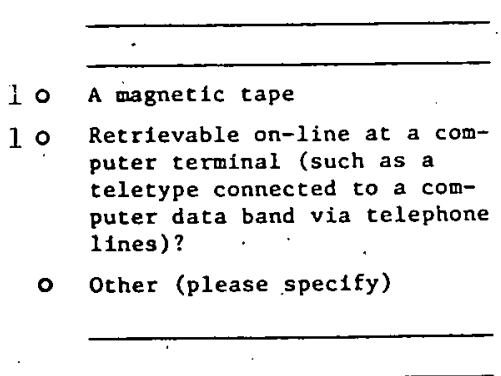

9. What additional services, if any would you like to have from varlous data centers:

- Brookhaven Cross-Section Center

- Atomic Data Center, Oak Ridge National Laboratory

- NBS

Prequency of use of centera

None $1-6$ times/yr $>6$ times/yr

$\begin{array}{llll}\text { BNL } & 09 & 02 & 01 \\ \text { ORNL } & 06 & 05 & 01 \\ \text { NBS } & 011 & 02 & 00\end{array}$


IV.C The American Society for Testing of Materials, E-10 Committee, Survey Questionnaire

1. Name: Phone

Chairman ASTM Subcommittee on

Address

2. Which ASTM Standards, under the jurisdiction of your Subcommittee, contain nuclear data (by ASTM number)

3. Which ASTM Standards, containing nuclear data, are referenced in the standards of your Subcommittee?

4. Circle the types of data which are referenced:

Type of data

(a) Half-lives of radioactive substances

(b) Isotopic abundances

(c) Nuclear masses

(d) Nuclear spins and moments.

(e) Neutron capture or fission cross-sections

(f) Nuclear decay modes and genetic (parent-daughter) reiationships

(g) Means of producing radioisotopes

(h) Energies and intensities of radiations (gamma rays, $X$-rays, beta particles, conversion electrons, alpha particles, other specify

(i) Detailed neutron reaction data (energy-dependent cross sections, resonance parameters)

(j) Neutron capture gamma spectra

*The ASTM survey has been sent to the chairmer of the various ASTM subcomittees. Eleven subcommittees have already returned their completed surveys. 
(k) Charged-particle or photo-induced reaction data (gross crosssections, cross-sections for specific levels, angular distributions, gamina-ray spectra)

(1) Nuclear level schemes

(m) Other types of data (specify)

5. How complete a listing of a given quantity is required (circle one or more)

a. All reported values

b. A few of the best reported values

c. The one most precise or accurate reported value.

d. A weighted average or adopted "best" value

e. Other (specify)

6. What sources of nuclear data are referenced and how well do they fulfill your requirements? (Mark: C for completely, $F$ for fairly well, or $P$ for poorly)
a) Other ASTM Standards
b) Table of Isotopes
-c) Nuclear Data Sheets (the journal Nuclear Data B and earlier looseleaf sheets)
d) Nuclide "wall" charts (BE, Battelle. NW or other versions)
e) BBL-325 (the "Barn Book")
f) "Light-element" compilations (by F. Ajzenberg-Belove or Endt and van der Leun, published in the journal Nuclear Physics, or other (specify)

g) Any "specialized" tables of specific properties, such as nuclear moments; nuclear masses, fundamental constants, electron binding energies, etc (specify) 
h) Data supplied by manufacturer or distributor of radioisotopes

i) Other (specify)

7. In what ways are they inadequate: (circle any answers which are applicable)

a. Do not cover some of the required categories of data

b. Cover too many categories of data

c. Not enough detail

d. Too much detail

e. Too difficult to interpret

f. Too far out of date

g. Other (specify)

8. Would you like to have the data in different forms, such as:

a. Another type of printed compilation (specify)

b. A magnetic tape

c. Retrievable on-line at a computer terminal (such as a teletype connected to a computer data bank via telephone lines)?

d. Other (specify)

9. Are there other ASTM Subcommittees which should be contacted?

10. Other comments: 
IV.D American Nuclear Society, Isotopes and Radiation Division Survey Questionnaire (Proposed)

1. Persoral Data

Same: $(005 \operatorname{son} a f)$

Occupacion:

Sare or Erployer: (opeiocal)

Inployer is a: a mulaca corporacton

$\square$ Govergons operzced Lascallation

$\square$ Governanc coresacs tescallation

$\square$ Cotvergic7 (nase of lept.

$\square$ o:her or coliege)

2. (2) Ac that tpo or facilly do you wort?
$\square$ zeacese
$\square$ acceleracor
$\square$ ocber

(b) What use do you rake or radioactiviter?
$\square$ eracers
$\square$ redteal dtazastes
$\square$ polluston sontrotsnz
$\square$ reacror rootrort=8
$\square$ resazeh

3. Shat types of cata co you requita? (cieck any rtici you usa).

INog of dict

$\square$ (a) Ealti-llves of́ zadloactive stiaczaces

$\square$ (b) Isocopic abundacess

$\square$ (c) Suclear zasses

$\square$ (d) Suclear spins and socarss

$\square$ (e) Teutzon capexiea or Itssion ctoss-sectlocs

$\square(f)$ vucleat decay zodes and gacetic (pareas-daugheer) zelactooshtps

$\square$ (g) Means of producl=3 :adtolsozopes

(s) Enerzias and tacanglefas of zaditutiong:

口 82ays

口x-гzys

$\square$ bees particles

$\square$ coriversira alecerons

$\square$ alpta parsicles

$\square$ ochae sadiactons (spec:ff)

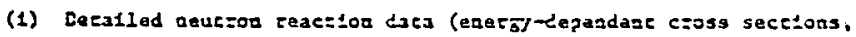
resocinca paracocers)

$\square$ (1) Seutzon expeure gama specesa

(k) Carzed-parziclo or phoes-laduced reaceton daca:

[D Grose cross sections (Excteutron Euncetona)

$\square$ cross-seceloas Eo: spectílc levels

$\square$ dagulas Discribustons

$\square$ Guma-ray spac:sa

(I) Suclast Level scheres

Q (a) Ocher tppes of daca (spectif)

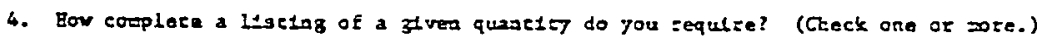

$\square$ ill reporzed values

$\square$ A tew of the bese rejorzed values

$\square$ The one cose proctse or accurace reporsed value

$\square$ A velgited avorage or adopeed "Bese" value

$\square$ Oehar (spec1f7)

5. P=erertad Form of Jate preacueation:

$\square$ wll chart(s) $\square$ card ilia

$\square$ book

$\square$ eagrecte expe

rectevabla on-clae at cospucen ceratial 